10.2478/v10367-012-0003-y

ANDRZEJ FELSKI

Polish Naval Academy

ALEKSANDER NOWAK

Gdansk University of Technology

\title{
LOCAL MONITORING OF EGNOS SERVICES
}

\begin{abstract}
Any SBAS system, as soon as it is permanently monitored by Earth stations, should deliver to the users correct information about quality of the augmented system. According to many sources of information, among them observations of authors, present accuracy of EGNOS service has accuracy about $1,5 \mathrm{~m}(95 \%)$, but availability of the service is still controversial. First of all the quality of the system is guaranteed only inside the border of the system coverage which still do not affect all territory of European Union, however observed accuracy at times is better outside this area than next door to the RIMS station. In addition there are evidences that availability has random character and essential differences as well as lack of correlation of this parameter in the different point of observations has been observed. So in author's opinion Local Monitoring of EGNOS service can contribute to better confidence of local users, especially in critical operations, like for example berthing of big ships or landing operations with EGNOS procedures. The example of EGNOS monitor which is working in real time and performed by the authors will be presented.
\end{abstract}

Keywords:

EGNOS, monitoring, accuracy of navigation, integrity.

\section{INTRODUCTION}

For many years quality of navigational systems has been referred first of all to the accuracy of the position. However now, commonly used GPS with some augmentations deliver so good accuracy, that for many users and in many applications accuracy is not so important question. For this reason more and more attention we address the other features of positioning services - its availability, integrity and continuity. It is especially important in critical applications.

The set of these parameters constitutes the complex information about integrity of the system which is understood as the "measure of the trust that can be placed in 
the correctness of the information delivered by the system' [5]. We must pay particular attention, that nowadays mentioned parameters are referred to navigation service, not to the system. It means the proper works of all elements and proper cooperation of them. In other words we can say the navigational service may deliver wrong information even if the receiver causes appearance of the correct work. The essence of this sentence is that integrity of the system should take into account environmental condition and it is possible the incorrect work of such systems composed from correctly working elements because of local influence. This is one of starting hypothesis of PECS project no. 98087 'The formal model of valuation of availability of EGNOS measurements with defined level of accuracy' conducted by Polish Naval Academy with cooperation of The Polish Air Navigation Services Agency (PANSA).

Composition of formal method of valuation EGNOS service parameters could be realized only on the basis of elaboration of long term observations (measurements) in chosen points which are distributed in logical manner.

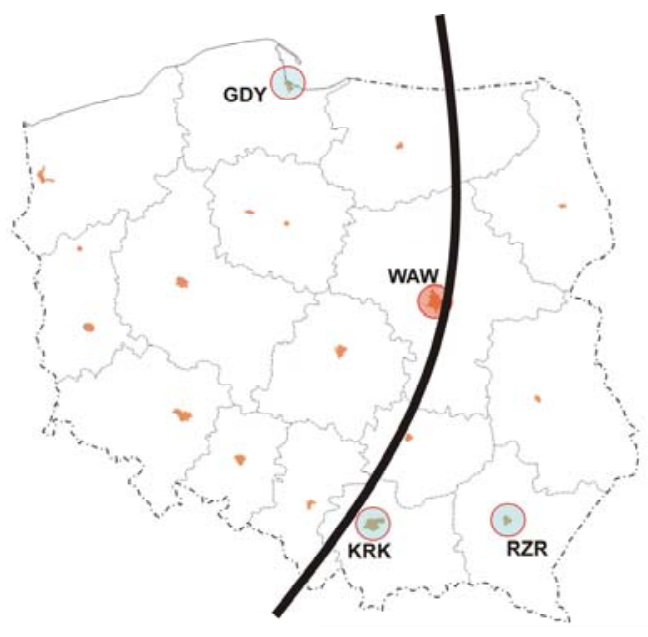

Fig. 1a. Distribution of measuring points. Line on the map shows approximately the border of APV I service according [2]

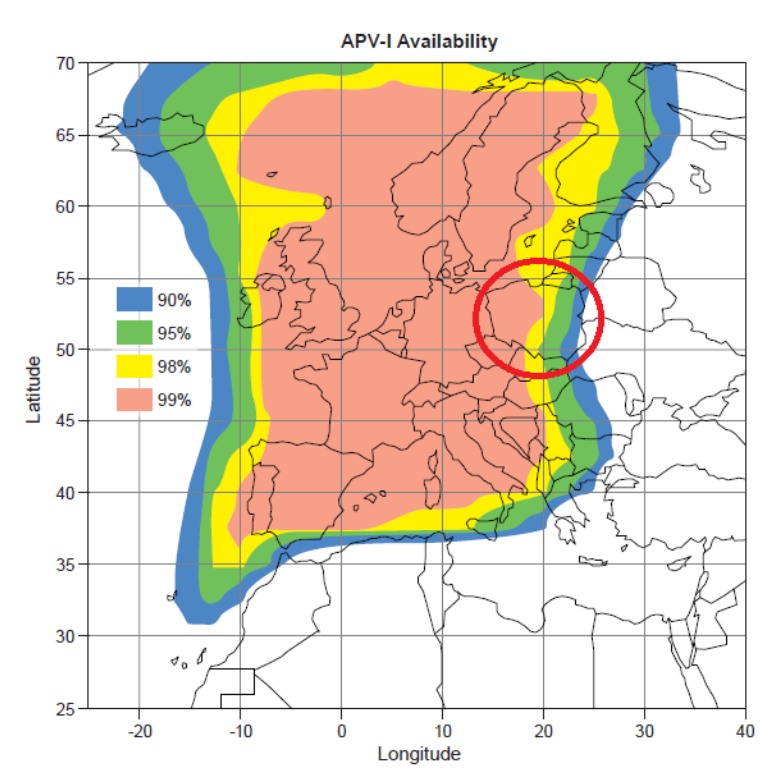

Fig. 1b. EGNOS APV-I Availability [3]

For this reason some campaigns in Warsaw (WAW), Krakow (KRK), Rzeszow (RZR) and in Gdynia (GDY) have been executed since October 2009 till May 2011 and the main results has been presented in [8] and during MT2012 Conference [6]. The main object of analyses was the accuracy and availability of EGNOS service in each point and for different receivers. Interesting observation is that accuracy is more dependent of the geographical place than of the receiver type. 
Finally the temporarily and spatial correlations of coordinates and its accuracy has been investigated. The key conclusion of this observations is that accuracy and availability of EGNOS service is depend on distribution of RIMS stations which is according theory, but important influence on this have local conditions. The similar is with the availability of the service. An evidence on this is the higher accuracy of the position in RZR point than in WAW or different availability of the service in the same time in each points. An additional aspect of this is the threat of jamming or spoofing of the GPS signal, which has fundamentally a local character which means, that it is not detectable through the network of the RIMS stations. All this leads for the conclusion about the need of the local monitoring of the EGNOS service for some users.

\section{THE REPEATABILITY OF COORDINATES}

The orbit of the GPS satellite is a twelve hours orbit, so similar values of geometrical coefficients (DOPs) will periodically repeat in the same point almost every 24 hours. EGNOS, as all augmentation systems, is a tool to correct the errors of the signal; however as EGNOS has no influence on the DOP, the geometrical coefficient does not change. The influence of geometrical factor on accuracy of the service is perceptible and will be evident when variability of the accuracy is analyzed in shorter sections than of twenty-four hours. For example, in the fig. 2 the fixes accuracy in Gdynia in every hour slots is presented for two following days.

The picture presents the mean values and standard deviation of longitude during one hour cycles (each cycle is 3600 registrations) measured by means of standard marine receiver. In each hour slot the mean value of longitude is different, as well as its standard deviation. However, it is clearly visible that the shift of the average position for the same time slots in the following days is very similar, as well as the standard deviation of coordinates in the same slots. From the fig. 2 it can be read, for example, the shift of the mean position easterly of true position for $0,5 \mathrm{~m}$ during the period between 0am and 1am. However, during the period since $2 \mathrm{am}$ to $3 \mathrm{am}$ the shift of mean longitude has been for $0,5 \mathrm{~m}$ westerly. In addition, different values of standard deviation should be noted, for example, in first and seven hour period.

In authors' opinion then changes of the average position and its different errors in each hour are perceptible and visible is repeatability of this process in vicinal days. This repeatability is a premise to forecasting of the quality of coordinates, as in following days we can observe similar behavior of coordinates, or different behavior of coordinates can signal different quality of the service in real time. If so, it is possible to monitor local behavior of the service and predict it in some manner. 


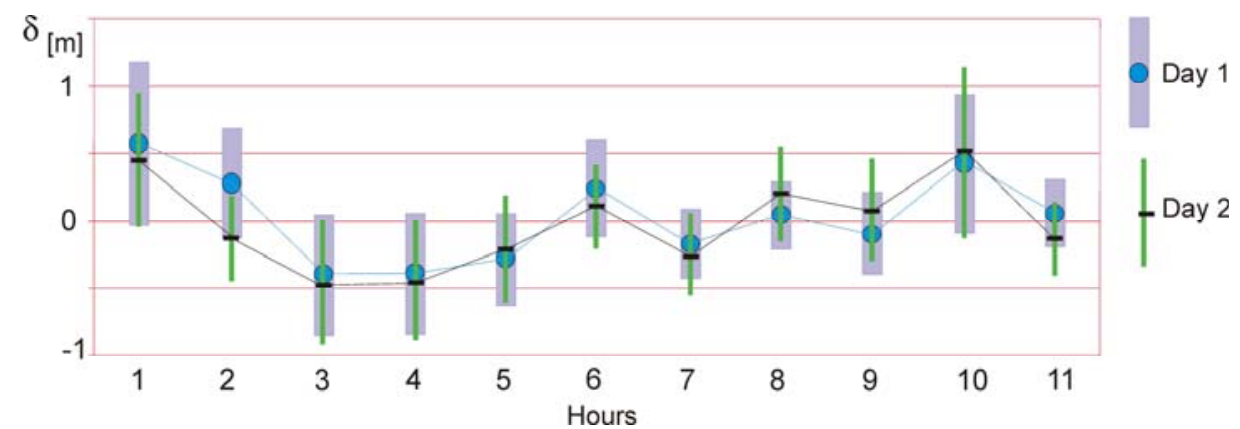

Fig. 2. Mean value of longitude and its standard deviation in particular hours in the two following days [6]

Table 1. Examples of shift of mean value of longitude and variation (presented in the fig. 2) [6]

\begin{tabular}{|c|c|c|c|c|}
\hline \multirow{2}{*}{$\begin{array}{c}\text { Hour } \\
\text { of day }\end{array}$} & \multicolumn{2}{|c|}{ Shift of the mean value } & \multicolumn{2}{c|}{ Variation } \\
\cline { 2 - 5 } & Day 1 & Day 2 & Day 1 & Day 2 \\
\hline 1 & $+0,51$ & +049 & 0,53 & 0,50 \\
\hline 2 & $+0,32$ & $-0,11$ & 0,41 & 0,33 \\
\hline 3 & $-0,47$ & $-0,49$ & 0,47 & 0,48 \\
\hline 4 & $-0,46$ & $-0,48$ & 0,48 & 0,47 \\
\hline 5 & $-0,32$ & $-0,24$ & 0,32 & 0,34 \\
\hline 6 & $+0,32$ & $+0,18$ & 0,31 & 0,31 \\
\hline 7 & $-0,23$ & $-0,32$ & 0,24 & 0,30 \\
\hline 8 & $+0,06$ & $+0,27$ & 0,24 & 0,33 \\
\hline 9 & $-0,09$ & $+0,14$ & 0,29 & 0,42 \\
\hline 10 & $+0,49$ & $+0,50$ & 0,50 & 0,54 \\
\hline 11 & $+0,06$ & $-0,09$ & 0,25 & 0,25 \\
\hline
\end{tabular}

Presented in fig. 2 alteration of the mean value of longitude (the similar exists for latitude) shows changes at least $\pm 0,5$ meter $(65 \%)$ when using the simple marine receiver. However, similar analysis shows that it is possible to calculate (forecast) accuracy for the next few hours. For example, from this picture: accuracy of the system during the first 5 hours of experiment is worse than the one from 5 to 9 . So local monitoring of EGNOS service is the interesting option for some users and promises them some benefit.

\section{'EGNOS FORECASTER' SOFTWARE MAIN FEATURES}

Software 'EGNOS Forecaster' was built in Delphi XE as multithread application for 32-bit platform of Windows. It is based on single dialog form with fixed size (no resizable). 
The main task of application is monitoring EGNOS service current work and on this basis is forecasting reliability characteristics of its. Appropriate work of the software demands two weeks observations at least. Shorter period could cause inadequate results of forecasting however monitoring function works correctly since first turn on. The main window of the software is shown in fig. 3 .

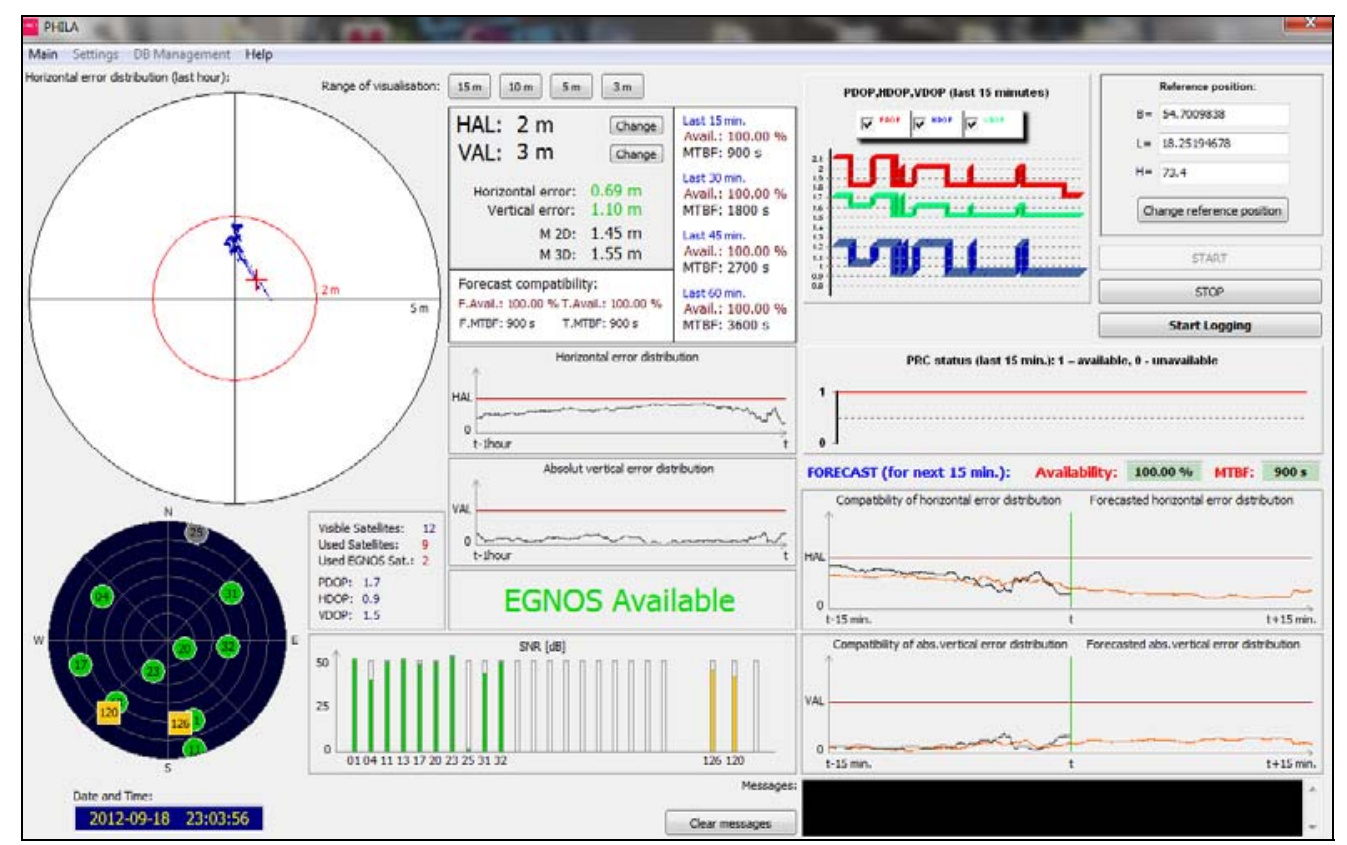

Fig. 3. Main window of 'EGNOS Forecaster' [own study]

The software could cooperate with every EGNOS receiver on condition that it is able to transmit at least GGA, ZDA and GSV messages in NMEA 0183 standard.

\section{Forecast calculation}

Forecast is calculated on the base of past EGNOS behavior observations where mean time between failures (mean time in state of work) and mean time to repair (mean time in state of failure) are taken into consideration. State of work is defined as:

The current horizontal fix errors are lower than HAL (horizontal alert limit) and current vertical error is lower than VAL (vertical alert limit) and EGNOS corrections are available.

In the other case, system is in state of failure. 
Horizontal and vertical errors are measured as distance between current position fixed by EGNOS receiver and true position (reference position) entered in the system. It is extremely important to enter accurate reference position. Otherwise the software will work incorrectly and the forecasts could significantly differ from reality. According to the algorithm only after two weeks of observations user obtains adequate forecast concerning estimated EGNOS availability and estimated mean time between failures (MTBF) for chosen values of HAL and VAL. The forecast is valid for next fifteen minutes. Longer period of observation causes more accurate forecasting but the last two preceding weeks are the most important (have the higher weight for the calculations). If user changes value of HAL or VAL the forecast will be recalculated. It allows to fit forecasting process to current navigational task.

Current observations are stored in data base and are used to forecast calculation and analyze EGNOS behavior. User obtains information about system availability and MTBF for last one hour (in fifteen minutes period) and forecast compatibility for last fifteen minutes. It allows evaluating service quality if process of forecasting is going correctly. The parts of main window of application which inform user about EGNOS availability, MTBF and forecast compatibility are shown in fig. 4.

\begin{tabular}{|c|c|c|}
\hline $\begin{array}{l}\text { HAL: } 2 \mathrm{~m} \\
\text { VAL: } 3 \mathrm{~m}\end{array}$ & $\begin{array}{l}\text { Change } \\
\text { Change }\end{array}$ & $\begin{array}{l}\text { Last } 15 \mathrm{~min} . \\
\text { Avail.: } 100.00 \% \\
\text { MTBF: } 900 \mathrm{~s}\end{array}$ \\
\hline $\begin{array}{l}\text { Horizontal error: } \\
\text { Vertical error: }\end{array}$ & $\begin{array}{l}0.69 \mathrm{~m} \\
1.10 \mathrm{~m}\end{array}$ & $\begin{array}{l}\text { Last } 30 \mathrm{~min} . \\
\text { Avail.: } 100.00 \% \\
\text { MTBF: } 1800 \mathrm{~s}\end{array}$ \\
\hline $\begin{array}{l}\text { M 2D: } \\
\text { M 3D: }\end{array}$ & $\begin{array}{l}1.45 \mathrm{~m} \\
1.55 \mathrm{~m}\end{array}$ & \multirow{2}{*}{$\begin{array}{l}\text { Last } 45 \mathrm{~min} . \\
\text { Avail.: } 100.00 \% \\
\text { MTBF: } 2700 \mathrm{~s} \\
\text { Last } 60 \mathrm{~min} . \\
\text { Avail.: } 100.00 \% \\
\text { MTBF: } 3600 \mathrm{~s}\end{array}$} \\
\hline $\begin{array}{l}\text { Forecast compatibili } \\
\text { F.Avail.: } 100.00 \% \text { T.A } \\
\text { F.MTBF: } 900 \mathrm{~s} \quad \text { T.M }\end{array}$ & $\begin{array}{l}\text { ail. } 100.00 \% \\
\text { TBF: } 900 \mathrm{~s}\end{array}$ & \\
\hline
\end{tabular}

Fig. 4. Information about EGNOS availability, MTBF and forecast compatibility [own study]

\section{EGNOS Service monitoring}

The EGNOS Forecaster allows not only forecasting EGNOS availability but also monitoring EGNOS current working as well. The main information presented to operator is current horizontal and vertical fix errors distribution with set value of horizontal alert limits (HAL) and vertical one (VAL) (see fig. 5). 

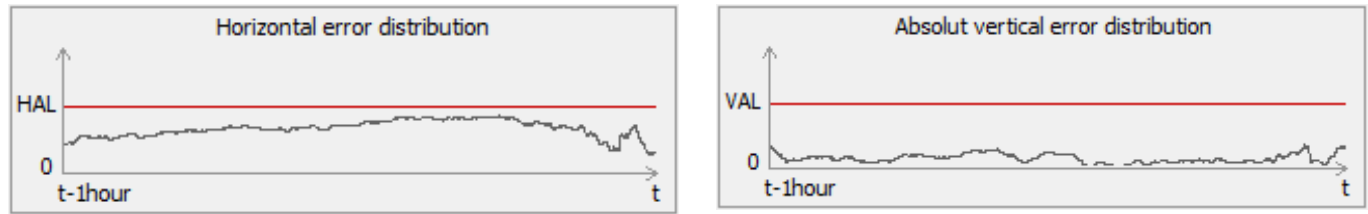

Fig. 5. Current distribution of horizontal and vertical errors of the service [own study]

Current values of horizontal and vertical fix errors, 2D and 3D mean-root-squared errors and set values of HAL and VAL are presented in digital form in addition (see fig. 6).

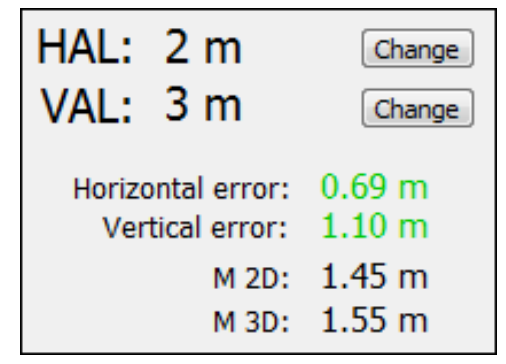

Fig. 6. Digital information about quality of the service [own study]

Behavior of the service in past time is presented also on the plot as well as the present fix and present set of HAL as red ring. User can change range of visualization depending on necessity.

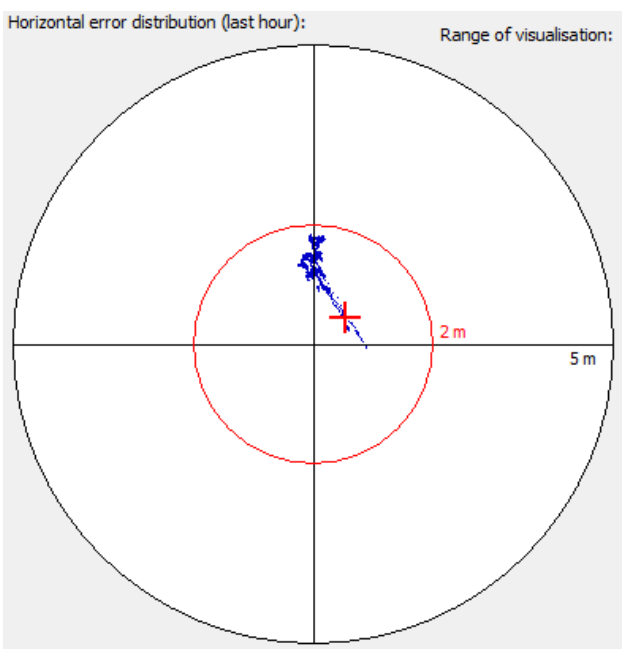

Fig. 7. The fix plot. Red cross is the present position [own study]

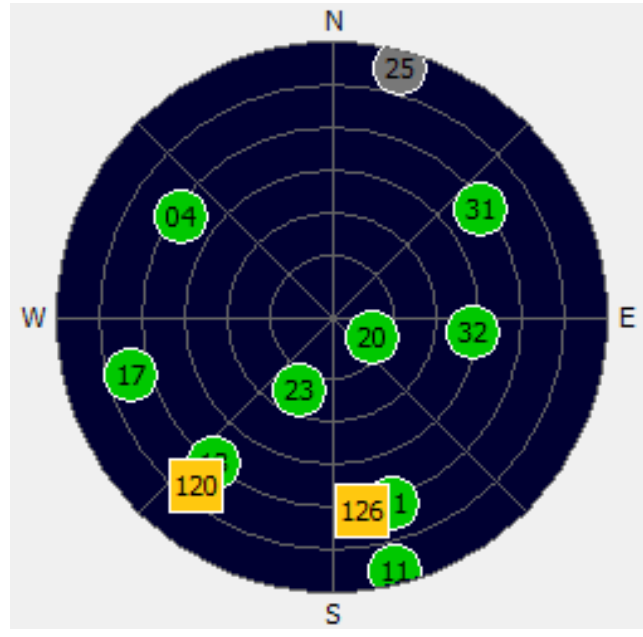

Fig. 8. The plot of satellites distribution [own study] 
For operator's needs different information about satellite constellation is presented in the plots or in table forms. Satellite constellation is presented in form of the plot (see fig. 8) and in SNR (signal to noise rate) diagram (see fig. 9). However additional table contains information about visible and used satellites and values of PDOP, HDOP and VDOP coefficients (see fig. 8).

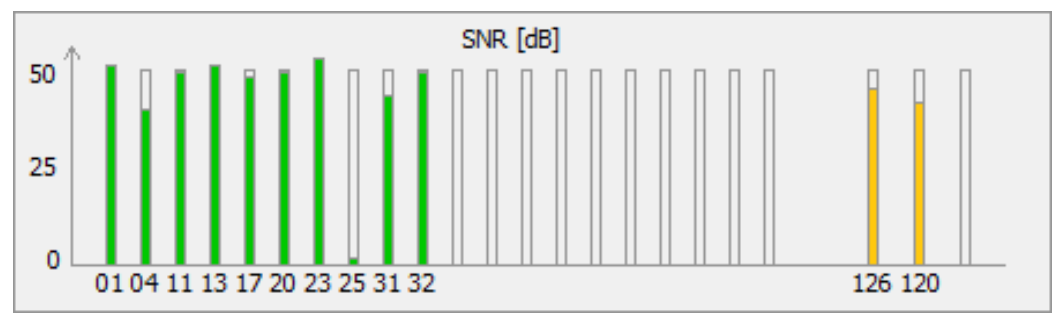

Fig. 9. The plot of SNR values for acquired satellite signals [own study]

$\begin{array}{ll}\text { Visible Satellites: } & 12 \\ \text { Used Satellites: } & 9 \\ \text { Used EGNOS Sat.: } & 2 \\ \text { PDOP: } & 1.7 \\ \text { HDOP: } & 0.9 \\ \text { VDOP: } & 1.5\end{array}$

Fig. 10. Tabularized information about satellite constellation and dilution coefficients [own study]

In addition, the plot of DOPs coefficients distribution (fig. 11) and PRC ststus (fig. 12) for last 15 minutes are presented in the system.

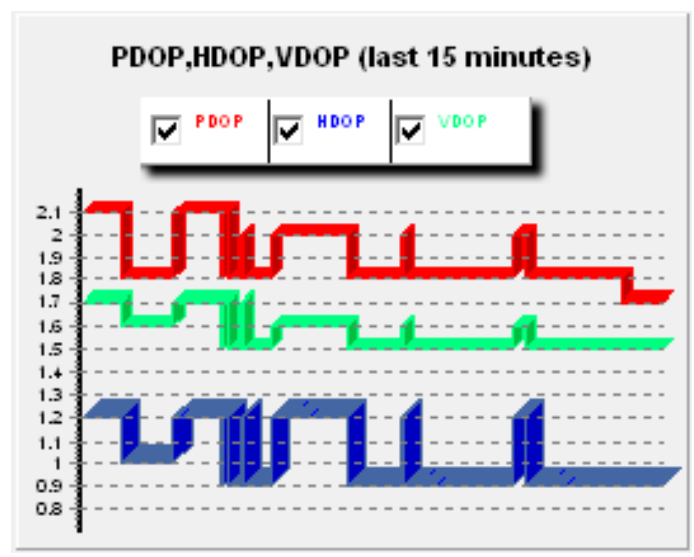

Fig. 11. The plot of coefficients of dilution of position for last 15 minutes [own study] 


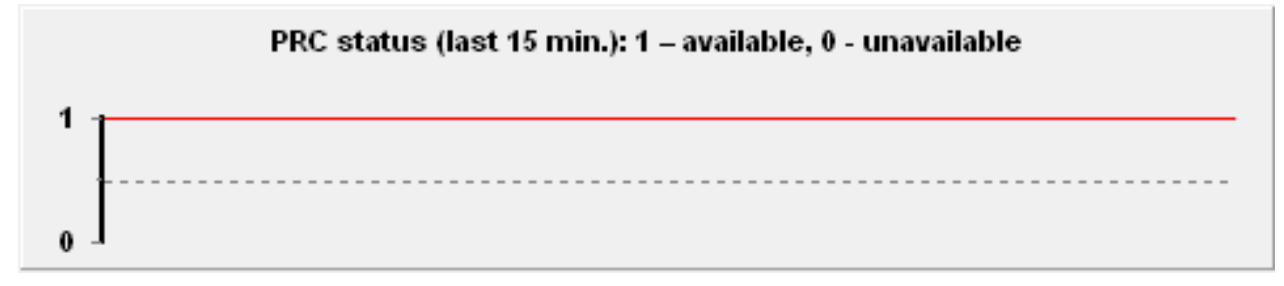

Fig. 12. The plot of PRC status for last 15 minutes [own study]

\section{SUMMARY}

The 'EGNOS Forecaster' software is still in process of development and evaluation. At present it working properly and allows to monitors EGNOS service and forecasts its behaviors in the future. The question is on how much faithfully and in which temporary horizon it reasonable. Many parameters and measures are calculated but not presented to the user nowadays. It needs to be taking into consideration which information is significant for operator. It allows defining the final shape of interface and fitting software to user's demands. The core of application, including database, is ready and further modifications need wilder consultations.

\section{REFERENCES}

[1] EGNOS - A Cornerstone of Galileo, 2007, SP-1303. ESA.

[2] EGNOS Monthly Performance Report March 2012 (essp_drd_6694_01_00_ publicreport_march2012.pdf), http://www.essp-sas.eu/monthly_performance_reports (17.04.2012).

[3] EGNOS Safety of Life Service Definition Document (2011), European Commission, Directorate-General for Enterprise and Industry.

[4] EGNOS Service Definition Document, 2009, Ref.: EGN-SSD OS v 1.0. Open Service, European Commissio,. Directorate-Generale for Energy and Transport.

[5] Federal Radionavigation Plan 2008, National Technical Information Service, Springfield, DOT-VNTSC-RITA-08-02/DoD-4650.5.

[6] Felski A., EGNOS Usefulness in Harbor Operations, MT2012 Conference, Barcelona.

[7] Felski A., Nowak A., Investigation of EGNOS Availability on the East Border of the System Coverage, ENC 2011 Conference, London. 
[8] Felski A., Nowak A., Woźniak T., Accuracy and Availability of EGNOS Results of Observations, Artifficial Satellites, 2011, Vol. 46, No. 3, pp. 111-118.

Received May 2012

Reviewed September 2012 